\title{
Cetacean biodiversity in the Bay of Biscay: Suggestions for environmental protection derived from citizen science data
}

Liam Matear*a, James R. Robbins ${ }^{\mathrm{b}, \mathrm{c}}$, Michelle Hale ${ }^{\mathrm{d}}$, Jonathan Potts ${ }^{\mathrm{a}}$

*Corresponding author:

Email: Liam.Matear@myport.ac.uk

Address: University of Portsmouth, Department of Geography,

Buckingham Building, Portsmouth, PO1 3HE, Hampshire, UK.

Affiliation:

1. Department of Geography, University of Portsmouth, Portsmouth, United Kingdom

2. ORCA, Portsmouth, United Kingdom

3. School of Biological and Marine Sciences, Plymouth University, Plymouth, United Kindgom

4. School of Earth and Environmental Sciences, University of Portsmouth, Portsmouth, United Kingdom

Colour print: Yes

Declaration of interest: None

\section{Abstract}

Cetacean communities face significant threats from adverse interactions with human activities such as bycatch, vessel collision, and environmental pollution. Monitoring of marine mammal populations can help to assess and safeguard marine biodiversity for future generations. Traditional surveys can be costly and time-consuming to undertake, but we explore the ability of citizen science to inform environmental assessments and subsequent conservation management. We use data collected from platforms of opportunity within the Bay of Biscay to investigate spatial changes in cetacean diversity, with the aim of identifying hotspots which may be suitable for further investigation and conservation. Seventeen species of cetaceans were recorded over a ten year period, many of which are data deficient in European waters (e.g. Bottlenose dolphin, Short-beaked common dolphin, Striped dolphin, Risso's dolphin, Longfinned pilot whale, Killer whale, Northern bottlenose whale, Cuvier's beaked whale, Sowerby's beaked whale and True's beaked whale). Biodiversity (determined by Simpson's Diversity index) ranged from 0.19 to 0.77 . The central and southern areas of the survey area indicated 
the highest biodiversity (0.65 - 0.77), and these locations may benefit most from protection as Important Marine Mammal Areas. We present a case for this designation, and discuss the benefits and limitations of citizen science for informing conservation action.

Keywords: IMMA, conservation management, citizen science, Bay of Biscay, cetacean, MPA 


\section{Introduction}

Historically, marine mammals have captivated public attention as charismatic megafauna which can inspire individuals to learn about marine ecosystems and promote environmental stewardship [1]. However, despite global efforts to conserve cetaceans, many populations are in decline, or are a small percentage of their historic abundance [2]. Today, cetacean species face a range of threats from human activities including vessel collisions, entrapment in fishing gear (bycatch), ghost gear entanglement, and the impacts of anthropogenic underwater noise [ 3-6]. These ongoing pressures highlight the need to improve existing conservation mechanisms, strengthen their implementation and compliance, and develop new policies which responds to the challenges posed to cetacean conservation [1].

Marine Protected Areas (MPAs) are distinct locations which are actively managed in order to protect and conserve their natural states [88]. Implemented through the designation of delineated boundaries, MPAs help regulate human activities and act as one of the key management mechanisms available to policy makers to mitigate adverse anthropogenic impacts. These areas can be managed with specific restrictions, such as fishing quotas, access controls, seasonal limitations and no-take zones [8-12]. Monitoring, often associated with MPAs, can help provide a clear understanding of the species and biodiversity, within area boundaries, which can inform management tailored to benefit both sessile and mobile organisms, including migratory species [13-15]. MPAs can help protect cetaceans throughout key life stages such as breeding and calving, but may be less effective for mobile species, as the boundaries of MPAs are usually static and may not protect species across their entire range. A key challenge faced when delineating MPA boundaries and determining threat mitigation policies is data paucity. Due to the behavioural characteristics of cetaceans, these highly mobile species can be challenging to observe, resulting in data gaps during periods when species are not visible at the sea surface [16,17].

Limited available data at appropriate spatial and temporal resolutions can hinder the outcomes of many conservation efforts [18]. Robust and large-scale surveys provide a snapshot of species occurrence [19]; however, infrequent or intermittent sampling can result in low temporal data representivity. Such knowledge gaps can limit our understanding of the causes and impacts of environmental pressures which, in turn, can restrict the effectiveness of management measures. These deficits can be addressed and mitigated using citizen science to collect high-resolution data, across a range of spatiotemporal scales, which might otherwise be infeasible to obtain through traditional research alone [20-23]. Additionally, citizen science can provide baseline datasets, from which ecosystem responses to future anthropomorphic changes can be compared, providing marine managers with a warning system for environmental change [18]. Marine mammal researchers within the field of environmental conservation are increasingly looking to develop citizen science projects as a means of increasing the amount of data collected which can be used to help identify areas of biological importance and temporal changes in species abundance [24]. Citizen science has the potential to benefit conservation science, policy-making and practice [25-28] by increasing survey effort and the amount of data collected, which in turn, can increase the likelihood of detecting environmental change [18]. In recent decades, the global use of citizen science has grown exponentially [29,30], and has highlighted a wide range of beneficial impacts for environmental conservation efforts, such as reduced financial constraints through volunteer schemes, improved public understanding of conservation issues and fine-grain data collection, which is imperative for monitoring, understanding and reducing anthropogenic impacts on biodiversity [28].

The Bay of Biscay offers a wide range of habitats for cetacean species, such as harbour porpoise (Phocoena phocoena), common bottlenose dolphin (Tursiops truncatus), striped dolphin (Stenella coeruleoalba), and Baleen whales (Balaenopteridae) [31,32]. Furthermore, 
bathymetry has been identified as a key factor influencing the species distribution, and habitat preferences of toothed whales within the Bay of Biscay, [33]. While these studies documented the spatial distributions of cetacean species within the study area, none have directly identified cetacean biodiversity hotspots.

Citizen scientists have been collecting data in the Bay of Biscay on cruise and ferry routes between Portsmouth and Santander since the mid-1990s. The use of these vessels as opportunistic research platforms has facilitated the collection of observational data over extended periods of time, with little or no cost $[33,34]$. Using trained volunteers to collect observational data on marine mammals from commercially active vessels, citizen science can further extend the longitudinal monitoring of marine mammals. Long-term data collected by citizen scientists can be used to highlight spatial trends, such as the distribution of biodiversity hot-spots, and help identify sites suitable for the implementation of MPAs and Important Marine Mammal Areas (IMMAs).

IMMAs are distinct locations identified as important for marine mammals, which may merit protection by being delineated as an area for conservation and or monitoring [35]. The introduction of IMMAs has been advocated to better support the specific needs of highly mobile marine megafauna, including cetaceans [35]. As a non-statutory variant of MPAs, IMMAs can be employed globally to establish biodiversity networks which support marine mammal populations [36]. Through the implementation of IMMAs, it is possible to assess, monitor and delineate biodiverse areas of high conservation importance. Information on species distribution, biodiversity and ecological communities can be used to inform the marine spatial planning of human activities, in order to promote the sustainable use of natural resources and mitigate adverse anthropogenic impacts [36]. Additionally, the spatial analysis of biodiversity and integration of accurate, representative ecological data into MPA design can assist in achieving species spillover effects [15] which can in turn facilitate interconnectivity between adjoining MPA/IMMA sites [37-39]. This is of particular importance when establishing protection mechanisms for migratory and mobile species, which otherwise may not be protected from human activities through static MPA networks.

This study utilized data from an ongoing citizen science project to investigate the spatial patterns of cetacean biodiversity in the Bay of Biscay and identify regions suitable for designation as MPAs or IMMAs.

2

\section{Material and methods}

2.1

\section{Data collection}

Citizen scientists, trained by ORCA (http://www.orcaweb.org.uk; [34], collected data on cetaceans aboard the Pont-Aven, operated by Brittany Ferries. The Citizen scientists working on ORCA-led surveys came from a range of backgrounds and ages, including students, working professionals, and retired senior citizens. Reasons for participation varied on an individual-specific basis. Some aimed to develop skills which may help them find employment opportunities, whereas others were high-level employees who currently work on marine mammal policy and used the surveys as opportunities to see the animals they work to protect. However, the majority of those who took part in ORCA surveys were not employed in a scientific field, nor aspired to, but were members of the public who were interested in conservation and therefore, contributed to scientific work as citizen scientists [40].

Prior to survey, each 'Marine Mammal Surveyor' undertook a day-long course, in which they were taught taxonomic identification skills, survey protocol and appropriate behaviour on the bridge of ships. Those who undertook longer surveys across the Bay of Biscay, which were included in this study, usually had greater levels of experience and would have completed at 
least three ORCA surveys in preparation for data collection. The teams of four generally comprised three experienced surveyors, and one with less experience to help develop less experienced observers.

The vessel followed a relatively fixed transect route from Plymouth, UK, to Santander, Spain, returning to Portsmouth, UK, through the Bay of Biscay (Fig. 1) in the summer months (March-October) between 2006 and 2016. Surveys were undertaken during daylight hours, under favourable conditions (swell height $\leq 2 \mathrm{~m}$, Beaufort Sea state $\leq 6$ ). The vessel travelled at consistent speed with an average of 20.4 knots. Observations were conducted from the bridge ( $21.75 \mathrm{~m}$ deck height) using $7 \times 50$ Opticron binoculars. When a sighting occurred, the species identity, certainty of identification, and GPS location were recorded.

Fig. 1

0 


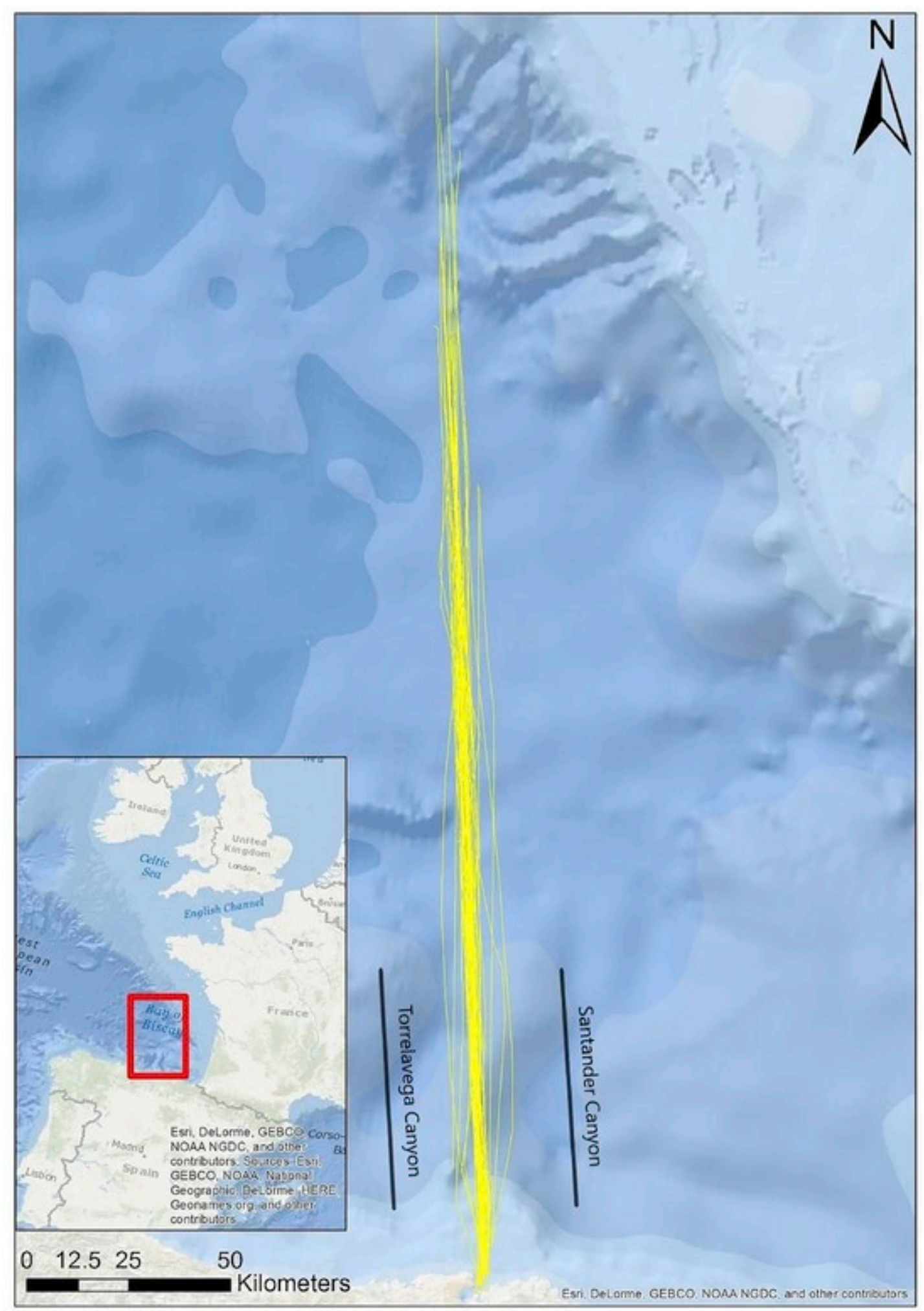

Study area - The Bay of Biscay. Survey transects and vessel effort for the Pont-Aven throughout the 10-year study period.

Survey teams consisted of four members, with two observers, one recorder, and one on rest. Individuals rotated roles every $30 \mathrm{~min}$, and observers only undertook searching effort for $30 \mathrm{~min}$ at a time, to avoid observer fatigue. Standard distance sampling methodology was used (see Ref. [34] for details of distance sampling protocol). The starboard observer collected data from $90^{\circ}$ starboard to $10^{\circ}$ port, whilst the port observer searched from $90^{\circ}$ port to $10^{\circ}$ starboard. This allowed $20^{\circ}$ overlap, should one observer miss species directly ahead. 
Simultaneously, the third active survey member recorded sightings and environmental conditions.

\section{2}

\section{Data management and quality control}

All data recorded by citizen scientists participating in ORCA surveys underwent checks by trained scientists to ensure a high level of quality control. Data retained by ORCA were stored in both physical and digital formats through the use of archives, log sheets and ESRI ArcGIS Geodatabases and relational databases. Both new and historic data were systematically checked using set protocols to ensure records are accurate, and that spatial data were formatted correctly. Additional checks were completed annually for any data collected within that year, to reduce the potential for erroneous data being archived.

\section{3}

\section{Statistical analyses}

Sixty-six crossings were carried out within the 10-year period. All sightings with uncertain species identification were omitted from statistical analyses. Data were analysed at a $10 \mathrm{~km}^{2}$ grid resolution based on spatial distribution within ArcMap 10.3 [41]. For each $10 \mathrm{~km}^{2}$ grid, species richness, evenness, and biodiversity were calculated using Past 3.15 software [42]. Simpson's Diversity Index 1-D was calculated to explain the relationship between overall abundance of individual species classifications (richness), and to examine how evenly individual taxa were spread (evenness) within each quadrat [43]. Richness was defined as the total number of species from a sample in a given location and evenness as a measurement of the relative abundance of species contributing to the richness of an area.

Simpson's Diversity Index (1-D) was calculated as follows:

where $n=$ Total no. individuals of a specific species; $N=$ Total no. individuals of all species. Evenness (E) was calculated as follows:

where D = Diversity; Dmax = the total no. of species present (maximum value of D).

3

\section{Results}

The statistical analyses included 1055 sightings and a total of 17 species were identified (Fig. 2; Appendix 1). Biodiversity indices were highest in the central and southern areas of the Bay of Biscay at around $44.9^{\circ} \mathrm{N}$ latitude. Biodiversity increased from the northern to the southern areas of the Bay of Biscay, with the highest value (0.77) located near the continental shelf slope of the Iberian Coast (Fig. 3). Species richness was highest in the southern-most areas of the bay nearest to the Santander Canyon, and species richness decreased in northern areas of the study area (Fig. 5). Species evenness was found to be highest (0.8-1) in close proximity to canyon habitats and both the northern and southern continental shelf slopes of the Bay of Biscay (Fig. 4). Areas of high biodiversity were also identified in the central, deep-water regions of the Bay of Biscay (Fig. 3). Diversity did not appear to be related to broad bathymetric conditions, with deep-water associated with both the highest (0.74-0.76) and the lowest (0.19) biodiversity indices (Fig. 3).

\section{Fig. 2}

- 0 


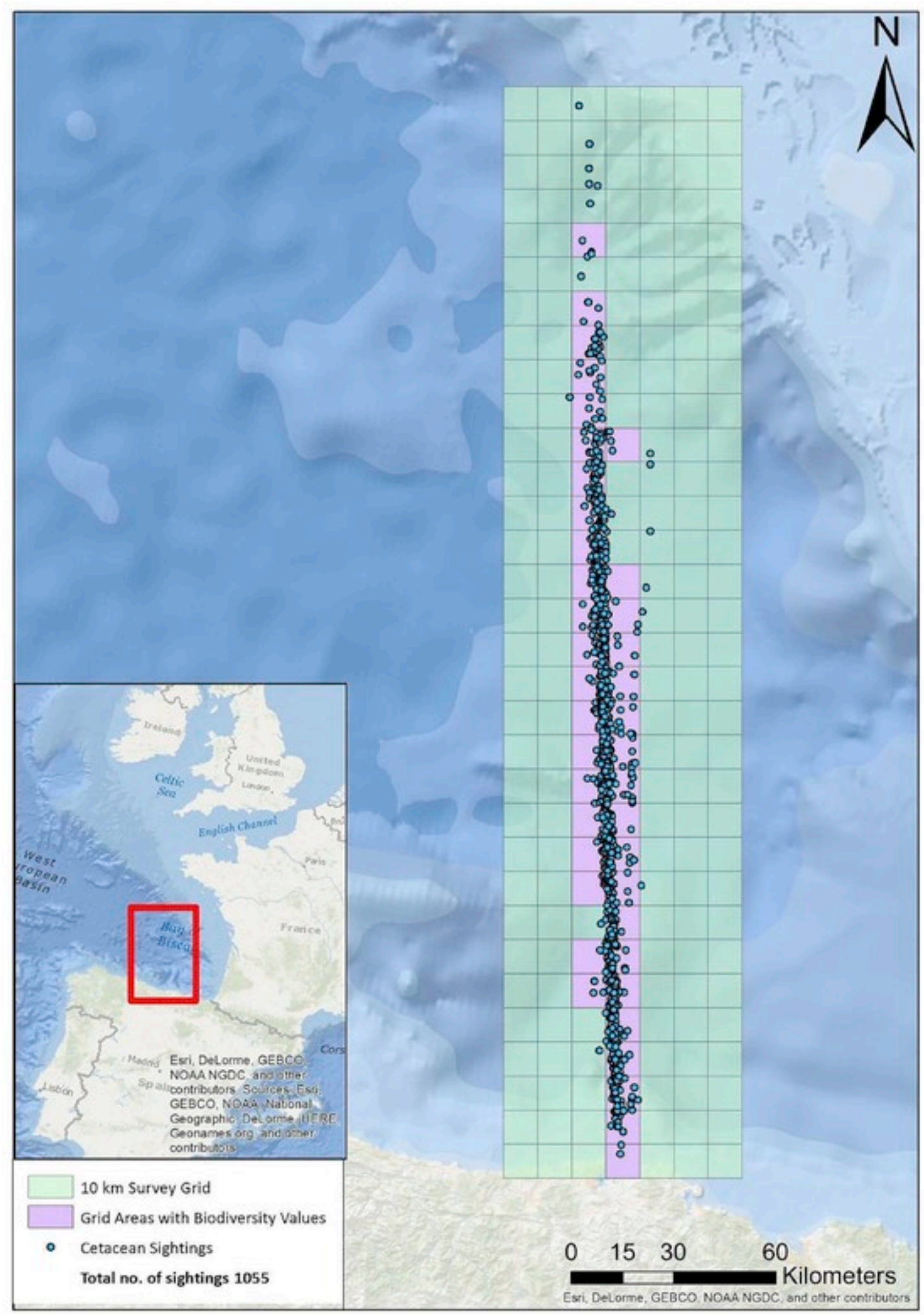

Analysed sightings and $10 \mathrm{~km}^{2}$ survey gridded areas with biodiversity values. Adapted from, Esri, DeLorme, GEBCO, \& NOAA NGDC (2017).

\section{Fig. 3}

0 


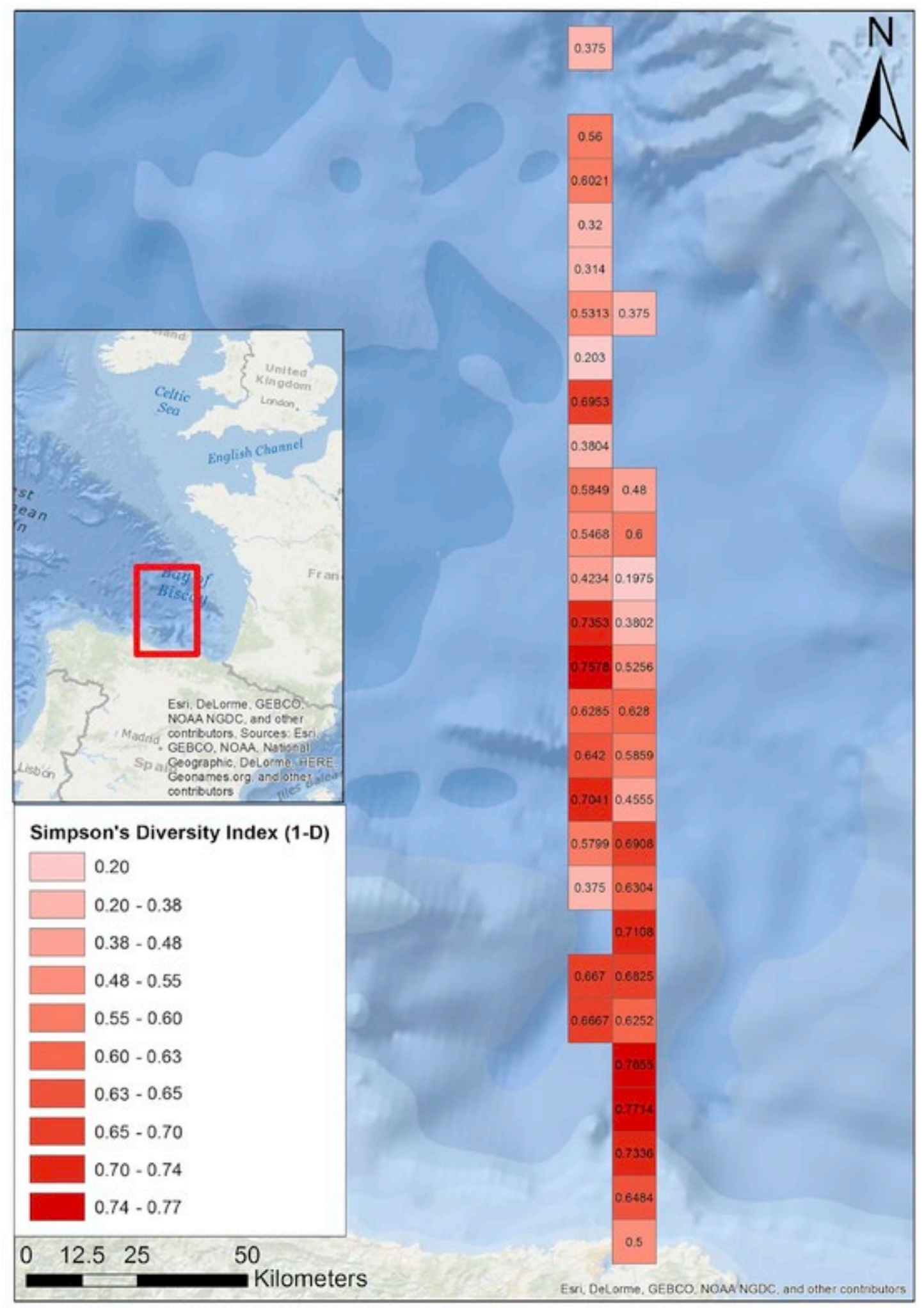

Spatial distribution of biodiversity from the 10-year dataset. All values given as Simpson's Diversity Index (1-D).

\section{Fig. 4}

0 


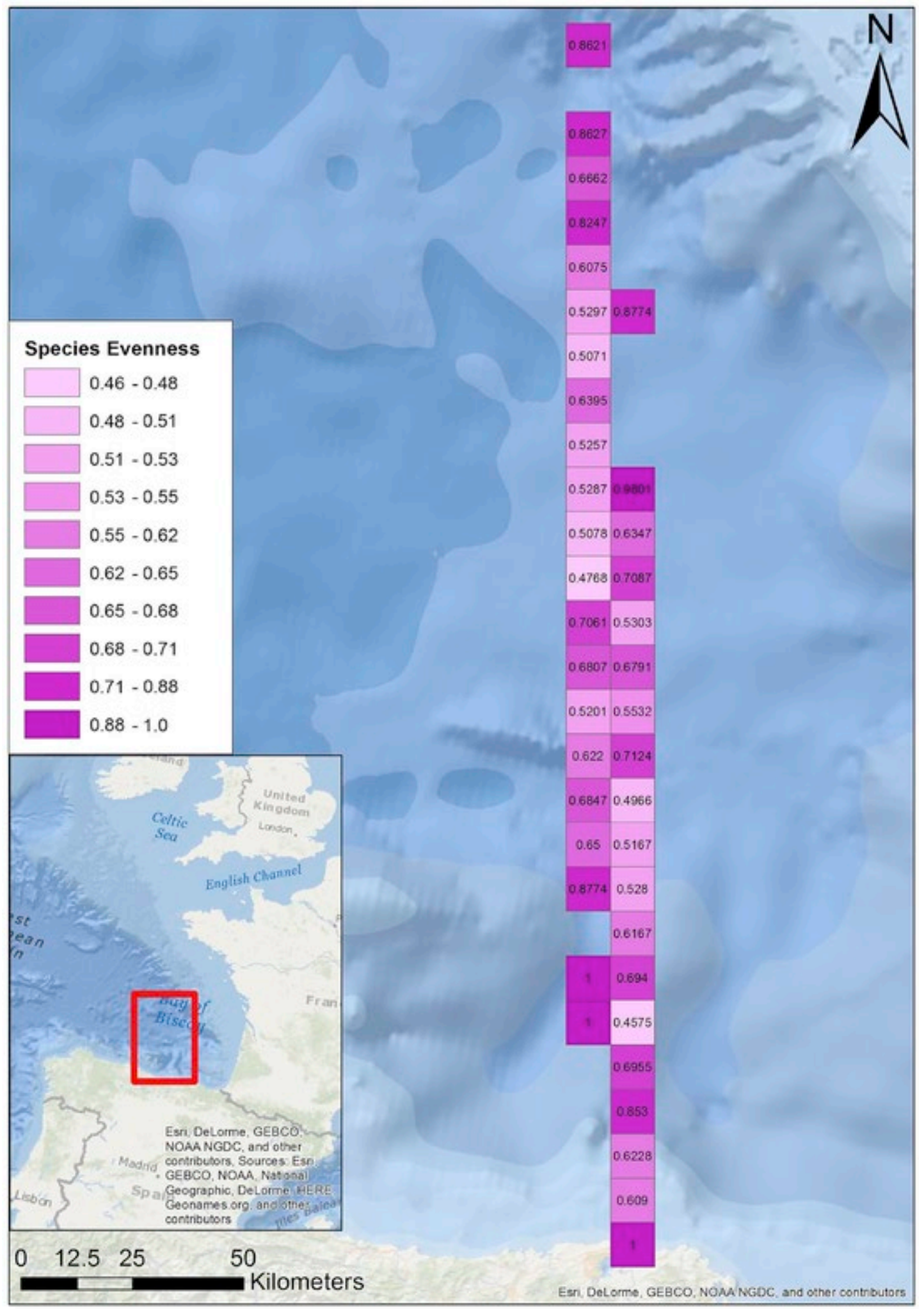

Spatial distribution of species evenness from the 10-year dataset.

Fig. 5

- 0 


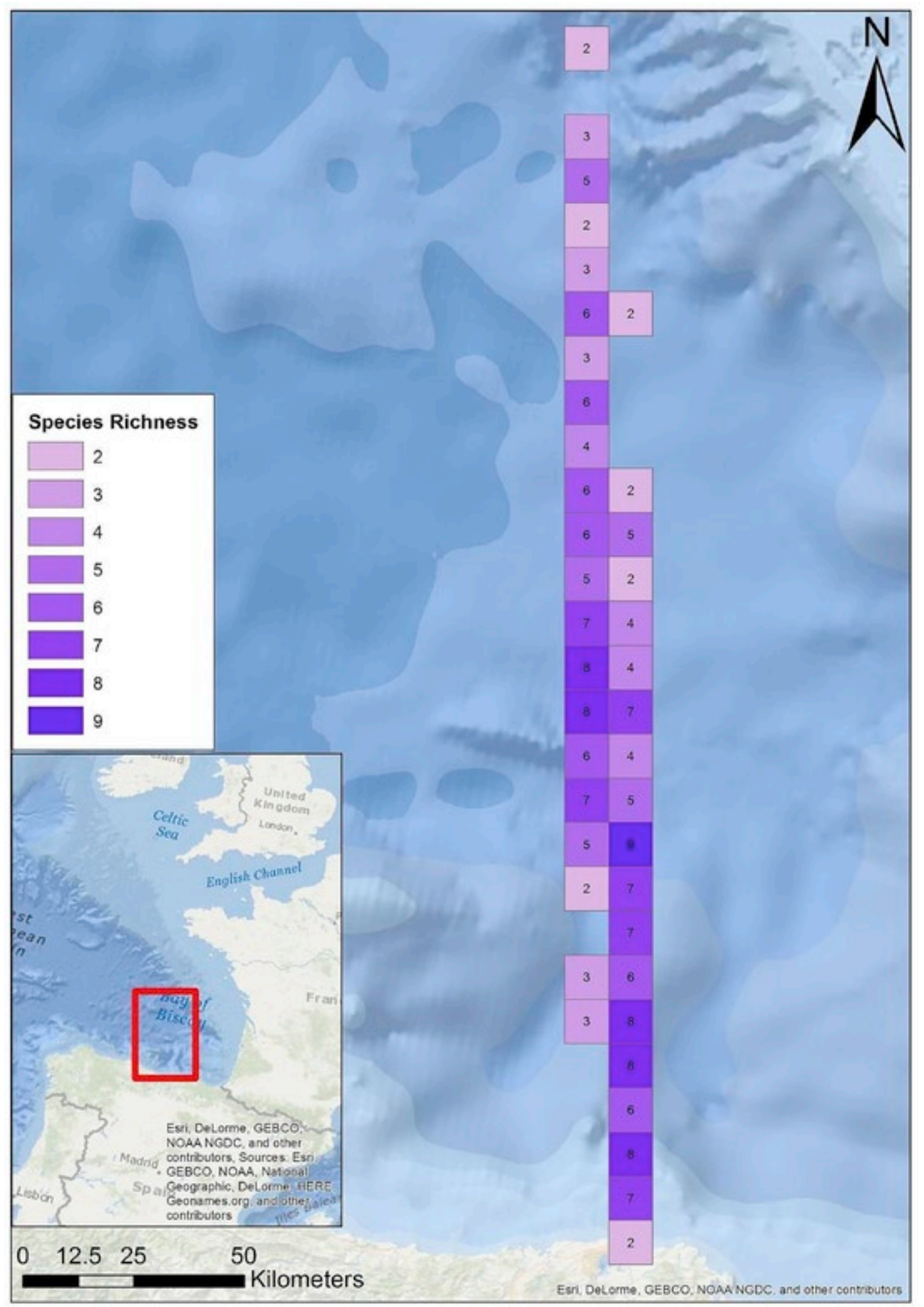

Spatial distribution of species richness from the 10-year dataset.

4

\section{Discussion}

Throughout the ten years of monitoring via citizen scientists, 17 species of cetaceans were recorded in the Bay of Biscay. Of these species, ten are listed as 'data deficient', two as 'near threatened', two as 'vulnerable', two as 'least concern', and one as 'endangered' on the IUCN Red List (Appendix 1; [7]. The area approximately $50 \mathrm{~km}$ north of Santander was the most 
diverse, with lower diversity towards the northern shelf edge. The areas of higher biodiversity fit the criteria outlined for IMMA implementation (Appendix B; $[35,36]$. The selection criteria comprise a range of key attributes designed to include as many potential biological, ecological and behavioural characteristics recognised to be important to marine mammals and prospective IMMAs need only satisfy one of the listed criteria and/or sub-criteria to be qualify for IMMA status [35]. The data from this study indicate that the Bay of Biscay meets these criteria as the habitats present are important to threatened and declining species; provide areas which consistently support populations throughout key life cycle stages, such as migration, feeding and calving; and has locations which support a high diversity of marine mammal species. The Bay of Biscay meets all categories of criteria (Criteria A, B, C, D).

The 10-year research period in this study indicates that despite potential fluctuations in environmental conditions which may affect the occurrence of cetaceans, the southern areas of the transect nearest to the Santander and Torrelevaga canyons were consistently more biodiverse than other areas. Diversity may have been highest in these areas as they provide a high variability of physiographic conditions that can support life [44], including nutrient upwelling leading to enhanced primary production, surface water convergence, transport of planktonic organisms, and the presence of thermoclines, baroclines and halocline gradients [ 45]. The geospatial distribution of biodiversity mirrored previous findings, with the highest recorded indices located near regions of steep, heterogeneous benthic habitats, such as nearcoastal submarine canyons [46,47].

The near-coastal areas closest to the Santander and Torrelevaga canyons may be of high conservation value and could benefit from MPA designation through further scientific research, protection of ecosystem services, and management of human activity $[48,49]$. However, as non-statutory mechanisms for marine conservation, IMMAs alone may not fully protect marine mammals within the Bay of Biscay, and therefore, should be used in combination with statutory management mechanisms, or as tools to further identify areas of conservation quality which could benefit from monitoring and legal protection. Management mechanisms such as IMMAs should be designed to be easily integrated into existing policies and institutional structures. This is important for transboundary marine management of highly mobile species such as cetaceans to ensure that all habitats that cetaceans depend upon throughout their biological cycles are represented [50].

The central, deep-water pelagic areas of the Bay of Biscay indicated high biodiversity indices, although these locations were not expected to support high biodiversity, as they do not have the typical characteristics considered necessary to support an abundance of life, such as diverse habitat heterogeneity or topography which may facilitate upwelling [51-57]. Unlike the near coastal hot-spots, the spatial distribution of biodiversity in deep-water habitats may be less influenced by physiographic and hydrographic features [44]. Therefore, the high biodiversity observed over deep-water habitats may be due to species-specific physiological and behavioural characteristics such as surfacing intervals for respiration, hunting, communication and display [58].

Many of the species recorded in the Bay of Biscay, including short-beaked common (Delphinus delphis), striped, and Risso's dolphins (Grampus griseus), long-finned pilot (Globicephala melas), Cuvier's beaked (Ziphius cavirostris) and common minke whales (Balaenoptera acutorostrata) are listed as 'data deficient' under European assessments by the IUCN Red List (Table 1; [32]). The designation of an IMMA could prioritise further monitoring to inform policy makers about the current status of the species and populations which use this area, and therefore facilitate appropriate conservation actions. Further monitoring in areas such as the Mediterranean Sea has aided the successful development of MPAs for cetaceans through improved understanding of natural environments [59]. Given the high biodiversity near the continental shelf slope of the Iberian Coast, these near coastal approaches meet IMMA 
selection criteria (Appendix B) and therefore, may benefit the most from IMMA protection. Further dedicated monitoring, or the analysis of existing datasets through the use of opportunistic citizen science could help address knowledge gaps and inform the protection of areas of importance, including those used by rare species.

4.1

\section{Applications of citizen science in cetacean conservation}

Citizen science has the capacity to complement dedicated professional surveys $[18,34]$. The combination of robust traditional surveys (e.g. Small Cetaceans in European Atlantic waters and the North Sea 'SCANS' and Cetacean Offshore Distribution and Abundance 'CODA') and long-term citizen science monitoring can highlight areas of importance such as those with high biodiversity to inform appropriate management [19,60]. Data collected through citizen science have been demonstrated to show similar trends to those collected by professional scientists [34 ]. Such similarities can be indicative of the potential value of citizen science, through validation of accuracy (dependent on methodology). However, citizen science is limited through other factors, including potential coverage and survey designs appropriate for platforms of opportunity and should therefore be seen as complementary to traditional surveys, rather than a replacement.

Cooperation between ferry companies and conservation organisations indicates that publicprivate-third sector collaboration is evolving positively [61]. The benefits of having ORCAtrained citizen scientists on board commercial and tourist vessels can extend into the transnational corporate world [62]. The integration of non-scientific organisations into academic research enables corporate social and environmental responsibility to be built into company policies. The willingness of commercial companies to welcome scientists onboard (e.g. Refs. $[33,34,63,64]$ is promising, and highlights that seafarers are interested in conserving the marine environment they work in. Brittany Ferries have been directly supporting dedicated research to reduce vessel collisions with large whales (Coxon, R., personal communication), with the Bay of Biscay highlighted as an area of concern. Furthermore, having volunteers on board non-research vessels has been shown to increase public awareness of marine environmental issues [65]. Members of the public who are aware of and sympathetic to environmental issues could become apathetic if their individual contributions, such as recycling, are perceived as futile within larger scale conservation efforts $[66,67]$. The use of citizen science can help engage individuals from non-technical backgrounds with academic research and civic activity, highlighting the importance of wider community engagement and participation [68]. Improved ecological understanding among the general public could enhance perceptions of the value of marine conservation efforts [69].

4.2

\section{Barriers between citizen science and conservation}

Citizen science has yet to be fully accepted by much of the scientific community given its innovative approach and relatively short history of widespread adoption, especially in the marine environment [70-72]. A survey of the scientific community found that citizen science was perceived to be less effective than traditional targeted research, potentially reducing its usage [70]. Key criticisms of citizen science research include weak study designs [73], inadequate participant training [29], poor standardisation of data and methodologies [74], and observational biases [75]. Poor survey methods can directly impact the accuracy and reliability of citizen science research, which in turn can erode confidence in the validity of findings on species abundance and density which are considered essential parameters for assessing population demographics [76,77].

Accuracy is considered essential when assessing species population demographics [76,77], and citizen science surveys have shown similar results to traditional surveys within the Bay of Biscay (e.g. Refs. [34,47]. Replicability and comparability of results highlights the value of 
citizen science, which can provide a cost-effective means of data collection across a wide range of spatiotemporal scales [33,34]. Surveys on platforms of opportunity can help bridge knowledge gaps through the provision of data at finer scales of resolution, which otherwise may not be achieved with traditional science alone, due to constraints such as funding. Both traditional surveys and the use of citizen science have numerous benefits, which can be used to complement each other to help overcome constraints and shortcomings.

However, citizen science has associated limitations, as in this study, the survey extent was constrained to the limited range of ferries which are selected for safe navigation and economic considerations rather than for facilitating marine scientific research [33]. Therefore, the spatial distribution of biodiversity cannot be extrapolated beyond the ferry routes. This survey design did provide an extensive temporal coverage of the survey area however, with ten years of data.

5

\section{Conclusions}

The results of this study show the long-term monitoring by citizen scientists can provide key information to identify areas of high biodiversity. Areas in the southern Bay of Biscay with varied bathymetry had the highest biodiversity and relatively rare cetacean species were also reported here, suggesting that these areas warrant further monitoring and likely protection. This area meets the criteria for IMMA designation, which would assist in the protection and conservation of the diverse cetacean species found in the Bay of Biscay.

\section{Declaration of interest}

None.

\section{Appendix A}

\section{Species list}

The species listed in Appendix A have been categorised using the International Union for Conservation of Nature (IUCN) Red List Classification to indicate the degree to which they are threatened. Species are assessed and classified into nine groups, Extinct (EX), Extinct in the Wild (EW), Critically Endangered (CR), Endangered (EN), Vulnerable (VU), Near Threatened (NT), Least Concern (LC), Data Deficient (DD), Not Evaluated (NE) [78]. The scale of the assessments within Appendix A are given at a global (G) scale, or within Europe (E).

\begin{tabular}{|c|c|c|c|}
\hline \multicolumn{4}{|c|}{ Species list and associated population trends } \\
\hline Species Common Name & Binomial & $\begin{array}{l}\text { IUCN Red List Classification (region of } \\
\text { assessment) }\end{array}$ & $\begin{array}{l}\text { Population } \\
\text { Trend }\end{array}$ \\
\hline Harbour porpoise & Phocoena phocoena & Vulnerable (E) & Decreasing \\
\hline Bottlenose dolphin & Tursiops truncatus & $D D(E)$ & Decreasing \\
\hline $\begin{array}{l}\text { Short-beaked common } \\
\text { dolphin }\end{array}$ & Delphinus delphis & $D D(E)$ & Unknown \\
\hline Striped dolphin & Stenella coeruleoalba & $D D(E)$ & Unknown \\
\hline Risso's dolphin & Grampus griseus & $D D(E)$ & Unknown \\
\hline Long-finned pilot whale & Globicephala melas & $D D(E)$ & Unknown \\
\hline Killer whale & Orcinus Orca & $D D(E)$ & Unknown \\
\hline
\end{tabular}




\begin{tabular}{|c|c|c|c|}
\hline Species Common Name & Binomial & $\begin{array}{l}\text { IUCN Red List Classification (region of } \\
\text { assessment) }\end{array}$ & $\begin{array}{l}\text { Population } \\
\text { Trend }\end{array}$ \\
\hline False killer whale & Pseudorca crassidens & Near Threatened (G) & Unknown \\
\hline Northern bottlenose whale & Hyperoodon ampullatus & $D D(E)$ & Unknown \\
\hline Cuvier's beaked whale & Ziphius cavirostris & $D D(E)$ & Unknown \\
\hline Sowerby's beaked whale & Mesoplodon bidens & $D D(E)$ & Unknown \\
\hline True's beaked whale & Mesoplodon mirus & $D D(E)$ & Unknown \\
\hline Sperm whale & Physeter macrocephalus & Vulnerable (E) & Unknown \\
\hline Common minke whale & $\begin{array}{l}\text { Balaenoptera } \\
\text { cutorostrata }\end{array}$ & Least Concern (E) & Unknown \\
\hline Humpback whale & Megaptera novaeangliae & Least Concern (E) & Increasing \\
\hline Sei whale & Balaenoptera borealis & Endangered (E) & Unknown \\
\hline Fin whale & Balaenoptera physalus & Near Threatened (E) & Unknown \\
\hline
\end{tabular}

Appendix B

\section{Important Marine Mammal Area Selection Criteria}

Criterion A - Species or Population Vulnerability

Areas containing habitat important for the survival and recovery of threatened and declining species.

\section{Criterion B - Distribution and Abundance}

\section{Sub-criterion B (i) - Small and Resident Populations}

Areas supporting at least one resident population, containing an important proportion of that species or population, that are occupied consistently.

\section{Sub-criterion B (ii) - Aggregations}

Areas with underlying qualities that support important concentrations of a species or population.

\section{Criterion C - Key Life Cycle Activities}

\section{Sub-criterion C (i) - Reproductive Areas}

Areas that are important for a species or population to mate, give birth, and/or care for young until weaning.

\section{Sub-criterion C (ii) - Feeding Areas}

Areas and conditions that provide an important nutritional base on which a species or population depends. 


\section{Sub-criterion C (iii) - Migration Routes}

Areas used for important migration or other movements, often connecting distinct life-cycle areas or the different parts of the year-round range of a non-migratory population.

\section{Criterion D - Special Attributes}

\section{Sub-criterion D (i) - Distinctiveness}

Areas which sustain populations with important genetic, behavioural or ecologically distinctive characteristics.

\section{Sub-criterion D (ii) - Diversity}

Areas containing habitat that supports an important diversity of marine mammal species.

Appendix C

\section{Supplementary data}

Supplementary data to this article can be found online at https://doi.org/10.1016/j.marpol.2019.103672.

\section{References}

iThe corrections made in this section will be reviewed and approved by journal production editor.

- [1]J.E. Reynolds, H. Marsh, T.J. Ragen, Marine mammal conservation, Endanger. Species Res.7 (2009) 2328.

- [2]J. Roman, S.R. Palumbi, Whales before whaling in the north atlantic, Science 301 (2003) 508-510.

- [3]A.J. Wright, N.A. Soto, A. Baldwin L., M. Bateson, C.M. Beale, C. Clark, T. Deak, E.F.Edwards, A. Fer nandez, A. Godinho, L.T. Hatch, A. Kakuschke, D. Lusseau, D. Martineau, M.L. Romero, L.S. Weilgart, B. A. Wintle, G. Notarbartolo-di-Sciara, V. Martin, Do marine mammals experience stress related to anthropogenic noise?, Int. J. Comp. Psychol. 20 (2) (2007) 274-316.

- [4]E.C.M. Parsons, S.J. Dolman, A.J. Wright, N.A. Rose, W.C.G. Burns, Navy sonar and cetaceans: just how much does the gun need to smoke before we act?, Mar. Pollut. Bull. 56(7) (2008) 1248-1257.

- [5]C.C. Monnahan, T. Branch, A.E. A. Punt, C.O. Onnahan, Do ship strikes threaten the recovery of endangered eastern North Pacific blue whales?, Mar. Mamm. Sci. 31 (2014) 279-297.

- [6]M. Stelfox, J. Hudgins, M. Sweet, A review of ghost gear entanglement amongst marine mammals, reptiles and elasmobranches, Mar. Pollut. Bull. 111 (1-2) (2016) 6-17.

- [7]IUCN. The IUCN red list of threatened species. Version 2018-2. Available from: https://www.iucn.org/theme/marine-and-polar/our-work/marine-protectedareas, 2019, 13 February2019.

- $\quad$ [8]T. Agardy, P. Bridgewater, M.P. Crosby, J. Day, P.K. Dayton, R. Kenchington, Dangerous targets? Unresolved issues and ideological clashes around marine protected areas, Aquat. Conserv. Mar. Freshw. Ecosyst. 13 (2003) 353-367.

- [9]K. Sainsbury, U.R. Sumaila, Fisheries ecosystem objectives into management of sustainable marine fisheries, including 'best practise' reference point and use of marine protected areas, Responsible Fisheries in the Marine Ecosystem 1 (2003) 343-361. 
- $\quad[10]$ T. Agardy, G.N. di Sciara, P. Christie, Mind the gap: addressing the shortcomings of marine protected areas through large scale marine spatial planning, Mar. Policy 35 (2011) 226-232.

- [11]J.S. Rossiter, A. Levine, What makes a successful marine protected area? The unique context of Hawaii's fish replenishment areas, Mar. Policy 44 (2014) 196-203.

- $\quad$ [12]K.L. Yates, D.S. Schoeman, C.J. Klein, Ocean zoning for conservation, fisheries and marine renewable energy: assessing trade-offs and co-location opportunities, J. Environ. Manag. 152(2015) 201-209.

- [13]M.J. Kaiser, Are marine protected areas a red herring or fisheries panacea?, Can. J. Fish. Aquat. Sci. 62 (2005) 1194-1199.

- [14]S.E. Lester, B.S. Halpern, K. Grorud-Kolvert, J. Lubchenco, B.I. Ruttenberg, S.D. Gaines, Biological effects within no-take marine reserves: a global synthesis, Mar. Ecol. Prog. Ser.384 (2009) 33-46.

- [15]H.E. Fox, M.B. Mascia, X. Basurto, A. Costa, L. Glew, D. Heinemann, Re-examining the science of marine protected areas: linking knowledge to action, Conservation Letters 5(2012) 1-10.

- [16]B.L. Taylor, M. Martinez, T. Gerrodette, J. Barlow, Y.N. Hrovat, Lessons from monitoring trends in abundance of marine mammals, Mar. Mamm. Sci. 23 (2006) 157-175.

- [17]J. Couto Di Toulio, T.B.R. Gandra, A.N. Zerbini, E.R. Secci, Diversity and distribution patterns of cetaceans in the subtropical southwestern Atlantic outer continental shelf and slope, PLoS One 11 (5) (2016) $1-24$.

- [18]J.A. Cigliano, H.L. Ballard, The promise and need of citizen science for coastal and marine conservation, Citizen Science for Coastal and Marine Conservation Part I 1 (2018) 3-14 (Chapter 1), doi:https://doi.org/10.4324/9781315638966.

- [19]P.S. Hammond, K. Macleod, P. Berggren, D. Borchers, L. Burt, A. Cañadas, G. Desportes, G.Donovan, A. Gilles, D. Gillespie, J. Gordon, L. Hiby, I. Kuklik, R. Leaper, K. Lehnert, M.Leopold, P. Lovell, N. Øien, C. Paxton, J.A. Vazquez, Cetacean abundance and distribution in European Atlantic shelf waters to inform conservation and management, Biol. Conserv.164 (2013) 107-122, doi:10.1016/j.biocon.2013.04.010.

- [20]F. Jiguet, R. Julliard, D. Couvet, A. Petiau, Modelling spatial trends in estimated species richness using breeding bird survey data: a valuable tool in biodiversity assessment, Biodivers. Conserv. 14 (13) (2005) 3305-3324.

- [21]D. Couvet, F. Jiguet, R. Julliard, H. Levrel, A. Teyssedre, Enhancing citizen contributions to biodiversity science and public policy, Interdiscip. Sci. Rev. 33 (10) (2008) 95-103.

- [22]D.S. Schmeller, P.Y. Henry, R. Julliard, B. Gruber, J. Clobert, F. Dziock, S. Lengyel, P.Nowicki, E. Der i, E. Budrys, T. Kull, K. Tali, B. Bauch, J. Settele, C. Van

Swaay, A. Kobler, V. Babij, E. Papastergiadou, K. Henle, Advantages of volunteer-based biodiversity monitoring in Europe, Conserv. Biol. 23 (2) (2009) 307-316.

- [23]V. Devictor, R.J. Whittaker, C. Beltrame, Beyond scarcity: citizen science programmes as useful tools for conservation biogeography, Divers. Distrib. 16 (3) (2010) 354-362.

- [24]C.B. Embling, E.M. Walters, S.J. Dolmanc, How much effort is enough? The power of citizen science to monitor trends in coastal cetacean species, Global Ecology and Conservation 3 (2015) 867-877.

- [25]C.B. Cooper, J. Dickinson, T. Phillips, R. Bonney, Citizen science as a tool for conservation in residential ecosystems, Ecol. Soc. 12 (2) (2007) 11.

- [26]F. Danielsen, N.D. T Burgess, P.M. Jensen, K. Pirhofer-Waizi, Environmental monitoring: the scale and speed implementation varies according to the degree of people's involvement, J. Appl. Ecol. 47 (6) (2010) 1166-1168. 
- [27]A. Cosquer, R. Raymond, A.C. Prevot-Julliard, Observations of everyday biodiversity: a new perspective for conservation?, Ecol. Soc. 17 (4) (2012) 2.

- $\quad$ [28]E.J. Theobald, A.K. Ettingerm, H.K. Burgess, L.B. DeBey, N.R. Schmidt, H.E. Froelich, C.Wagner, J. HillerisLambers, J. Tewksbury, M.A. Harsch, J.K. Parrish, Global change and local solutions: tapping the unrealised potential of citizen science for biodiversity research, Biol. Conserv. 181 (2015) 236-244.

- [29]C.C. Conrad, K.G. Hilchey, A review of citizen science and community-based environmental monitoring: issues and opportunities, Environ. Monit. Assess. 176 (2011) 273-291.

- $\quad$ [30]C. Kullenberg, D. Kasperowski, What is citizen science? A scientometric meta-analysis, PLoS One 11 (1) (2016). https://doi.org/10.1371/journal.pone.0147152 e0147152.

- $\quad$ [31]C.D. MacLeod, T. Brereton, C. Martin, Changes in the occurrence of common dolphins, striped dolphins and harbour porpoises in the English Channel and Bay of Biscay, Marine Biological Association United Kingdom 89 (2009) 1059-1065.

- $\quad$ [32]S. Laran, M. Authier, A. Blanck, G. Doremus, H. Falchetto, P. Monestiez, E. Pettex, E.Stephan, O. Van Canneyt, V. Ridoux, Seasonal distribution and abundance of cetaceans within French waters - part II: the Bay of Biscay and the English Channel, Deep Sea Res. Part II Top. Stud. Oceanogr. 141 (2017) 31-40.

- [33]J. Kiszka, K. Macleod, O. van Canneyt, D. Walker, V. Ridoux, Distribution, encounter rates, and habitat characteristics of toothed cetaceans in the Bay of Biscay and adjacent waters from platform-of-opportunity data, ICES (Int. Counc. Explor. Sea) J. Mar. Sci. 64 (2007) 1033-1043.

- [34]J.R. Robbins, L. Babey, C.B. Embling, Citizen science in the marine environment: a case-study estimating common dolphin densities in the north-east Atlantic, PeerJ Preprints 7(2019). https://doi.org/10.7287/peerj.preprints.27569v1 e27569v1.

- [35]MMPATF. IMMA selection criteria. Marine mammal protected areas task force. Available at: https://www.marinemammalhabitat.org/activities/immas/imma-criteria/, 2016.

- $\quad$ [36]UNEP CMS, Important marine mammal areas (IMMAs). 1st Meeting of the Sessional Committee of the CMS Scientific Council (ScC-SC1) UNEP/CMS,/ScC-SC1/Doc.10.4.2.1, 2016, pp. 1-4.

- [37]J.J. Bell, Connectivity between island marine protected areas and the mainland, Biol. Conserv. 141 (2008) 2807-2820.

- [38]L. Botsford, D. Brumbaugh, C. Grimes, J. Kellner, J. Largier, M. O’Farrell, Connectivity, sustainability, and yield: bridging the gap between conventional fisheries management and marine protected areas, Rev. Fish Biol. Fish. 19 (2009) 69-95.

- $\quad$ [39]S. Planes, G.P. Jones, S.R. Thorrold, Laval dispersal connects fish populations in a network of marine protected areas, Proc. Natl. Acad. Sci. 10 (2009) 5693-5697.

- [40]J. Shirk, H. Ballard, C. Wilderman, T. Phillips, A. Wiggins, R. Jordan, E. McCallie, M.Minarchek, B. L ewenstein, M. Krasny, R. Bonney, Public participation in scientific research: a framework for deliberate design, Ecol. Soc. 17 (2) (2012).

- [41]ESRI, ArcGIS Desktop: Release 10.3, Environmental Systems Research Institute, Redlands, CA, 2016.

- $\quad$ [42]Ø. Hammer, D.A.T. Harper, P.D. Ryan, PAST: paleontological statistics software package for education and data analysis, Palaeontol. Electron. 4 (1) (2001) 9.

- [43]E.H. Simpson, Measurement of diversity, Nature 163 (1949) 688.

- $\quad$ [44]A. Gomez de Segura, P.S. Hammond, J.A. Raga, Influence of environmental factors on small cetacean distribution in the Spanish Mediterranean, J. Mar. Biol. Assoc. U. K. 88 (6) (2008) 1185-1192. 
- [45]T. Lamont, M. García-Reyes, S. Bograd, C. Van der Lingen, W. Sydeman, Upwelling indices for comparative ecosystem studies: variability in the benguela upwelling system, J. Mar. Syst. 188 (2017), doi:10.1016/j.jmarsys.2017.05.007.

- [46]M. Laborde, Spatial Distribution of Cetaceans in the Bay of Biscay and Implications of the Marine Strategy Framework Directive for Their Conservation, Universidade de Lisboa Faculdade de Ciencias, 2008, doi:10.13140/RG.2.2.22520.96000.

- [47]E. Marcos, J.M. Salazar, R. De Stephanis, Cetacean diversity and distribution in the coast of Gipuzkoa and adjacent waters, southern Bay of Biscay, Munibe 58 (2010) 221-231.

- [48]C.M. Roberts, Fully-protected Marine Reserves: a Guide. WWF Endangered Seas Campaign, 1250 24th Street, NW, Washington, DC 20037, USA and Environment Department, University of York, York, YO10 5DD, UK, 2000 Available from:. http://assets.panda.org/downloads/marinereservescolor.pdf.

- [49]H.F. Upton, E.H. Buck, Marine protected areas: an overview, Marine Protected Areas (2010) 1-24.

- [50]K. Holzinger, C. Knill, Causes and conditions of cross-national policy convergence, J. Eur. Public Policy 12 (2005) 775-796.

- [51]C.A. Hui, Undersea topography and distribution of dolphins of the genus Delphinus in the southern California Bight, J. Mammal. 60 (1979) 521-527.

- [52]J. Forcada, A. Aguilar, P.G.H. Evans, W.F. Perrin, Distribution of common and striped dolphins in temperate waters of eastern North Atlantic, Eur. Res. Cetaceans 4 (1990) 64-66.

- [53]M.F. Baumgartner, The distribution of Risso's dolphin (Grampus griseus) with respect to the physiography of the northern Gulf of Mexico, Mar. Mamm. Sci. 13 (1997) 614-638.

- [54]S.K. Hooker, H. Whitehead, S. Gowans, Marine protected area design and the spatial and temporal distribution of cetaceans in a submarine canyon, Conserv. Biol. 13 (1999) 592-602.

- $\quad$ [55]R.W. Davis, G.S. Fargion, N. May, T.D. Leming, M. Baumgartner, W.E. Evans, L.J. Hansen, Physical habitat of cetaceans along the continental slope in the north-central and western Gulf of Mexico, Mar. Mamm. Sci. 14 (1998) 490-507.

- [56]R.W. Davis, J.G. Ortega-

Ortiz, C.A. Ribic, W.E. Evans, D.C. Biggs, P.H. Ressler, R.B. Cady, R.R. Leben, K.D. Mullin, B. Wursig, Cetacean habitat in the northern oceanic Gulf of Mexico, Deep Sea Res. 49 (2002) 121-142.

- [57]K. MacLeod, R. Fairbairns, B. Fairbairns, A. Gill, J. Gordon, C. Blair-Myers, E.C.M.Parsons, The seasonal distribution of the minke whale (Balaenoptera acutorostrata) in relation to physiographic factors and potential prey off the Isle of Mull, Scotland, Mar. Ecol. Prog. Ser. 277 (2004) 263-274.

- [58]J.V. Redfern, M.C. Ferguson, E.A. Becker, C. Hyrenbach, K. Barlow, M.F. Kaschner, K.A.Forney, K.A . Baumgartner, P. Ballance, P. Fauchald, Techniques for cetacean habitat modelling: a review, Mar. Ecol. Prog. Ser. 310 (2006) 271-295.

- [59]A. Cañadas, R. Sagarminaga, S. Garcia-Tiscar, Cetacean distribution related with depth and slope in the Mediterranean off southern Spain, Deep Sea Res. Part I 49 (2002) 2053-2073.

- [60]P.S. Hammond, K. Macleod, D. Gillespie, R. Swift, A. Winship, A. Cañadas. Cetacean Offshore distribution and abundance in the European atlantic (CODA). Available from: http://biology.standrews.ac.uk/coda/documents/CODA Final Report 11-2-09.pdf, 2009.

- [61]E. Darko, Private Sector and NGO Engagement, Overseas Development Institute, DfID, 2014 Available from:. https://assets.publishing.service.gov.uk/media/57a089eee5274a27b2000325/Private Sector and NG O Engagement.pdf. 
- [62]ORCA. About us: what we do. Available at: http://www.orcaweb.org.uk/about/what-we-do,2015.

- [63]T. Brereton, D. Wall, P. Cermeno, D. Curtis, A. Vasquez, A. Williams. Cetacean monitoring in northwest European waters. The atlantic research Coalition (ARC). Available from: http://www.marinelife.org.uk/media/27187/brereton_2001_arc\%20report.pdf, 2001.

- [64]R. Williams, S. Hedley, P. Hammond, Modelling distribution and abundance of Antarctic baleen whales using ships of opportunity, Ecol. Soc. 11 (1) (2006) 1-28.

- [65]B.K.Y. Kwan, J.H.Y. Cheung, A.C.K. Law, S.G. Cheung, P.K.S. Shin, Conservation education program for threatened Asian horseshoe crabs: a step towards reducing community apathy to environmental conservation, J. Nat. Conserv. 35 (2017) 53-65.

- [66]J. Connell, J. Fien, H. Lee, D. Sykes, D. Yencken, 'If it doesn't directly affect you, don't think about it': a qualitative study of young people's environmental attitudes in two Australian cities, Environ. Educ. Res. 5 (1999) 95-113.

- [67]H. Harness, H. Drossman, The environmental education through filmmaking project, Environ. Educ. Res. 17 (2011) 829-849.

- [68]S.R. Arnstein, A ladder of citizen participation, J. Am. Plan. Assoc. 35 (4) (1969) 216-224.

- [69]A.Y. Lo, S.M. Chow, S.M. Cheung, Significance of perceived social expectation and implications to conservation as a case study, Environ. Manag. 50 (2012) 900-913.

- $\quad[70]$ H. Riesch, C. Potter, Citizen science as seen by the scientists: methodological, epistemological and ethical dimensions, Public Underst. Sci. 23 (1) (2013) 107-120.

- [71]A.I.T. Tulloch, H.P. Possingham, L.N. Joseph, J. Szabo, T.G. Martin, Realizing the full potential of citizen science monitoring programs, Biol. Conserv. 165 (2013) 128-138.

- [72]C.B. Cooper, J. Shirk, B. Zuckerberg, The invisible prevalence of citizen science in global research: migratory birds and climate change, PLoS One 9 (9) (2014).

- [73]M. Krasny, R. Bonney, Environmental education through citizen science and participatory action research, Environmental Education or Advocacy: Perspectives of Ecology and Education in Environmental Education, Cambridge University Press, 2005, pp. 291-318.

- [74]D.N. Bonter, C.B. Cooper, Data validation in citizen science: a case study from ProjectFeederWatch, Front. Ecol. Environ. 10 (6) (2012) 305-307.

- [75]J. Dickinson, B. Zuckerberg, D.N. Bonter, Citizen science as an ecological research tool: challenges and benefits, Annu. Rev. Ecol. Evol. Syst. 41 (2010) 149-172.

- [76]A. Liebhold, J. Gurevitch, Integrating the statistical analysis of spatial data in ecology, Ecography 25 (5) (2002) 553-557.

- [77]D.I. MacKenzie, J.D. Nichols, A.J. Royle, K.H. Pollock, L.L. Bailey, J.E. Hines, Occupancy Estimation and Modelling: Inferring Patterns and Dynamics of Species Occurrence, 1, Academic Press, 2006, pp. 53-68.

- [78]IUCN, IUCN Red List Categories and Criteria:, second ed., IUCN, Gland, Switzerland and Cambridge, UK, 2012 4. 32. Version 3.1.

- [88]IUCN. Marine protected areas. Available from: https://www.iucn.org/theme/marine-and-polar/ourwork/marine-protected-areas, 2019. 